\title{
Erratum to: How does dexamethasone influence surgical outcome after laparoscopic Nissen fundoplication? A randomized double-blind placebo-controlled trial
}

Mario Schietroma • Maurizio Giuliani - Giovanni Zoccali • Francesco Carlei - Zuleyka Bianchi - Anca Gabriela Daniloiu • Gianfranco Amiccucci

Published online: 16 September 2010

(C) Springer-Verlag 2010

Erratum to: Updates Surg (2010) 62:47-54

DOI 10.1007/s13304-010-0009-8

Unfortunately, the names of the authors had been given incorrectly in our article. The authors are: Mario Schietroma, Maurizio Giuliani, Giovanni Zoccali, Francesco Carlei, Zuleyka Bianchi, Anca Gabriela Daniloiu, Gianfranco Amiccucci as now given above and below.

The online version of the original article can be found under doi:10.1007/s13304-010-0009-8.

M. Schietroma ( $\square)$ · M. Giuliani · G. Zoccali · F. Carlei · Z. Bianchi · A. G. Daniloiu · G. Amiccucci

Dipartimento di Scienze Chirurgiche, Facoltà di Medicina e

Chirurgia, Presso Ospedale San Salvatore, Università degli Studi

dell'Aquila, Edificio Delta 6, 67100 Coppito (AQ), Italy

e-mail: schietroma2001@yahoo.it 